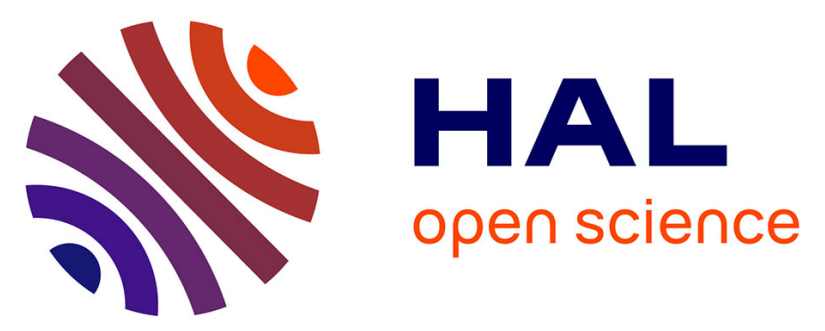

\title{
Cranial meningiomas in 411 NF2 patients with proven gene mutations: Clear positional effect of mutations, but absence of female severity effect on age at onset
}

Miriam Jane Smith, Jenny E Higgs, Naomi L Bowers, Dorothy Halliday, Joan Patterson, James Gillespie, Susan M Huson, Simon R Freeman, Simon Lloyd, Scott A Rutherford, et al.

\section{To cite this version:}

Miriam Jane Smith, Jenny E Higgs, Naomi L Bowers, Dorothy Halliday, Joan Patterson, et al.. Cranial meningiomas in 411 NF2 patients with proven gene mutations: Clear positional effect of mutations, but absence of female severity effect on age at onset. Journal of Medical Genetics, 2011, 48 (4), pp.261. 10.1136/jmg.2010.085241 . hal-00604044

\section{HAL Id: hal-00604044 \\ https://hal.science/hal-00604044}

Submitted on 28 Jun 2011

HAL is a multi-disciplinary open access archive for the deposit and dissemination of scientific research documents, whether they are published or not. The documents may come from teaching and research institutions in France or abroad, or from public or private research centers.
L'archive ouverte pluridisciplinaire $\mathbf{H A L}$, est destinée au dépôt et à la diffusion de documents scientifiques de niveau recherche, publiés ou non, émanant des établissements d'enseignement et de recherche français ou étrangers, des laboratoires publics ou privés. 


\section{$\underline{\text { Cranial meningiomas in } 411 \text { NF2 patients with proven gene mutations: Clear }}$}

positional effect of mutations, but absence of female severity effect on age at

onset

MJ Smith ${ }^{1}$, JE Higgs ${ }^{1}$, NL Bowers ${ }^{1}$, D Halliday ${ }^{2}$, Patterson $^{3}$, J Gillespie ${ }^{4}$, SM

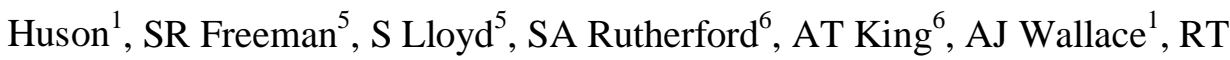

$$
\text { Ramsden }^{5} \text {, DGR Evans }{ }^{1}
$$

1. Department of Genetic Medicine, St Mary's Hospital, Manchester Academic Health Sciences Centre (MAHSC), University of Manchester, Manchester, UK.

2. Department of Clinical Genetics, The Oxford Radcliffe Hospitals NHS Trust, Oxford, UK

3. Dept of Medical Genetics, Addenbrookes NHS Trust, Hills Road, Cambridge, UK.

4. Department of Neuroradiology, Salford Royal Foundation Trust, Manchester, UK

5. Department of Otolaryngology, Manchester Royal Infirmary, Manchester, UK

6. Department of Neurosurgery, Salford Royal Foundation Trust, Manchester, UK

Professor D Gareth R Evans

Department of Genetic Medicine, St Mary's Hospital

Oxford Road

Manchester M13 9WL

United Kingdom

Tel: $\quad$ +44 (0)161 2766228

Fax: $\quad+44(0) 1612766145$

Email: gareth.evans@cmft.nhs.uk

Word Count: 2368 


\begin{abstract}
Background: Meningiomas have been reported to occur in approximately $50 \%$ of neurofibromatosis type 2 (NF2) patients.

The NF2 gene is commonly biallelically inactivated in both schwannomas and meningiomas. The spectrum of NF2 mutations consists mainly of truncating (nonsense and frameshift) mutations. A smaller number of patients have missense mutations, which are associated with a milder disease phenotype.

Methods: We analysed cumulative incidence and gender effects as well as the genotype-phenotype correlation between the position of the NF2 mutation and the occurrence of cranial meningiomas in a cohort of 411 NF2 patients with proven NF2 mutations.

Results and Conclusion: Patients with mutations in exon 14 or 15 were least likely to develop meningiomas. Cumulative risk of cranial meningioma to age 50 years was $70 \%$ for exons $1-3,81 \%$ for exons $4-6,49 \%$ for exons $7-9,56 \%$ for exons $10-13$ and $28 \%$ for exons 14-15. In our cohort of 411 patients, we found no overall gender bias for occurrence of meningioma in NF2 disease. Cumulative incidence of meningioma was close to $80 \%$ by 70 years of age for both males and females, but incidence by age 20 years was slightly increased in males (male, $25 \%$; female, $18 \%$; $\mathrm{p}=0.023$ ). Conversely we also found an increased risk of meningiomas in women with mosaic NF2 disease.
\end{abstract}

\title{
Key words:
}

Meningioma, NF2, Merlin, mutation position effect 


\section{Introduction}

Neurofibromatosis type 2 (NF2) is an autosomal dominant disease characterised by the development of schwannomas, meningiomas and ependymomas, with the great majority of patients having bilateral schwannomas of the eighth cranial nerve $[1,2]$. Intracranial meningiomas are the second most common type of tumour found in NF2 patients, although the factors determining which individuals will develop meningiomas are unclear.

Spinal meningiomas may occur in up to one third of NF2 patients [3, 4]. However, they are frequently asymptomatic and many are only detected incidentally when imaging is carried out for an unrelated purpose. Spinal meningiomas are not screened for routinely and they are difficult to distinguish from schwannomas by imaging alone. Therefore, the exact prevalence is unclear.

The NF2 gene is biallelically inactivated in most schwannomas and meningiomas. The spectrum of NF2 mutations consists mainly of truncating (nonsense and frameshift) mutations $[5,6]$. A smaller number of patients have missense mutations, which are associated with a milder disease phenotype [7, 8]. Although the NF2 tumour spectrum and molecular findings are reasonably well described, description of disease severity has largely been related to mutation type rather than position within the NF2 gene $[7,8,9,10,11,12]$. A positional effect has only been described for splice site mutations, with mutations in the 3' end of the gene leading to milder disease [13, 14].

The NF2 gene product, Merlin, is a cytoskeletal protein that provides a functional link between the cell membrane and the actin cytoskeleton [15]. The N-terminus contains a FERM (4.1, ezrin, radixin, moesin) domain, which is responsible for binding various interacting proteins [16]. This can be further divided into three sub-domains. The first sub-domain (amino acids 20-100) has a ubiquitin-like structure, the second sub- 
domain (amino acids 101-215) has an acyl CoA binding protein-like structure and the third sub-domain (amino acids 216-313) has a structure similar to phosphotyrosine binding protein (PTB), pleckstrin homology domain (PH), or Enabled/VASP Homology 1 (EVH1). These three domains fold into a "cloverleaf" conformation [17]. The FERM domain is followed by an $\alpha$-helical domain (amino acids $314-478$ ) which can fold to bring the C-terminal domain (amino acids 479-595) close to the N-terminus. In its folded conformation Merlin is inhibited from binding actin.

The absence of somatic mutations in exons 14 and 15 of the NF2 gene in sporadic meningiomas $[5,6]$ prompted us to investigate whether a positional effect of germline mutations existed for meningiomas. We also felt the evidence base for counselling regarding gender effect on severity of meningioma disease was also relatively under investigated for NF2. Here describe the rates of cranial meningioma onset in a cohort of 411 patients with NF2 in whom a germline or mosaic mutation has been identified and compare severity of disease with relation to the position of the NF2 mutation. We also investigate the effect of gender on meningioma risk. 


\section{Materials and Methods}

We undertook a retrospective review of 411 patients from our database with a diagnosis of NF2. Patients were referred to the Regional Molecular Genetics Service at St Mary's Hospital in Manchester for mutational analysis. Only individuals with a proven germline or mosaic mutation were included.

Mutation analysis of the patients' peripheral blood was undertaken as previously described $[18,19]$. Briefly, genomic DNA samples were amplified with primers for all 17 exons of the NF2 gene and direct sequencing was used in addition to Multiple Ligation Dependant Probe amplification (MLPA) to identify mutations. Where no mutation was identified, further analysis using DNA of the patient's tumour tissues, where available, was undertaken using a previously described technique [18].

All patients have had cranial MRI scans to identify meningioma disease presence and number of tumours. Previously operated meningiomas were included in numbers. Age at initial diagnosis of meningioma was recorded.

Kaplan-Meier analysis was used to assess age at onset of cranial meningioma. Mutation groups were defined as 1) exons 1-3, which encode the first FERM subdomain of the Merlin protein product; 2) exons 4-6, which encode the second FERM sub-domain; 3) exons 7-9 encoding the third FERM sub-domain; 4) exons 10-13, coding for the $\alpha$-helical domain and 5) exons 14-15, which encode the C-terminal domain. Large deletions removing the promoter and exon 1 and whole gene deletions were excluded from the analysis. Multi-exon deletions within the gene were grouped according to the first exon affected by the deletion. Numbers of patients with and without cranial meningiomas were compared using the chi-squared test. 


\section{Results}

In our cohort of 411 NF2 patients, 215 were male and 196 were female. Sixty six individuals were mosaic. In total 199/411 (48\%) NF2 patients had at least one cranial meningioma that was identified on MRI scan or at surgery.

\section{Effect of mutation position}

The position and prevalence of each mutation type identified in the NF2 gene and the proportion of individuals in each category with at least one cranial meningioma are presented in Table 1. As expected, the prevalence of cranial meningiomas was lower in individuals with a missense mutation $(26 \%)$ or splicing mutation (35\%), compared with truncating mutations (nonsense or frameshift, 58\%). No significant difference was seen between patients with nonsense or frame shift mutations and those with a large deletion.

Mutations within the first two FERM sub-domains had the greatest impact in risk of cranial meningioma (61\% and 58\% with meningioma, respectively). Mutations occurring in the third FERM sub-domain or within the $\alpha$-helical domain conferred a lesser risk of cranial meningioma (39\% and $45 \%$, respectively). The $\alpha$-helical domain appears to confer a higher risk than the third FERM domain, although the difference is not significant and is due to a few high risk mutations in the second half of exon 10, at the junction between these two domains. Mutations occurring at junctions between other domains were also seen to have an increased risk (Figure 1b). Patients with mutations in the C-terminal domain were the least likely to develop a cranial meningioma (24\%).

The Kaplan-Meier plot in Figure 1 shows a significant difference between the 5' and 3' mutations: exons 1-3, exons 4-6, exons 7-9 and exons 10-13 compared to exons 14-15 ( $\mathrm{p}<0.0001)$. Cumulative risk of cranial meningioma to age 50 years was $70 \%$ for 
exons $1-3,81 \%$ for exons $4-6,49 \%$ for exons $7-9,56 \%$ for exons $10-13$ and $28 \%$ for exons 14-15. The hazard ratio (HR) for mutations in exons 7-15 was 0.499 (95\% CI 0.376 to 0.663$)$ compared to mutations in exons $1-6(\mathrm{p}<0.0001)$. A similar hazard ratio of $0.48(0.27-0.81)$ was obtained by comparing truncating mutations in exons 14 and 15 with truncating mutations in exons 1-6 (Figure 2). The risk of cranial meningioma up to age 50 years was only $44 \%$ for truncating mutations in exons 14 and15 (similar to the risk for all mutation types in these exons) compared to $83 \%$ for truncating mutations in exons 1-6 (HR 0.48; $\mathrm{p}=0.0065)$. The average age of diagnosis for a cranial meningioma in patients with a mutation in exons 1-13 was 24.8 years, compared to exons 14 and 15 of 34.2 years.

\section{Gender effect}

Overall, no gender bias was observed between the number of males $(105 / 215$, $49 \%)$ and females $(94 / 196,48 \%)$ who developed at least one cranial meningioma (Figure 3a). By 50 years of age approximately $60 \%$ of both men and women had developed a cranial meningioma and by 60 years this increased to over $70 \%$. There was no overall significant difference in age of cranial meningioma onset between males and females with the curves closely aligned after 30 years of age. However, these totals disguise an age related effect. There was a significantly greater risk of males developing a cranial meningioma below 20 years of age compared to females $(\mathrm{p}=0.023)$. The gender differences for age at onset were sustained across all mutation position groups with cranial meningiomas being detected earlier in males in the first 20 years of life.

Overall, a higher number of cranial meningiomas was found in females than males ( $\mathrm{p}<0.0001)$. The 105 males with cranial meningiomas had a total of 223 cranial meningiomas (median 2; range 1-10; mean per patient 1.05), whereas the 94 females 
with cranial meningiomas had a total of 282 cranial meningiomas (median 2; range 1-10; mean per patient 1.42 ). However, this was mainly due to a small number of females with $\geq 4$ cranial meningiomas, four of whom had 10 cranial meningiomas each, compared to only one male with 10 cranial meningiomas.

\section{Effect of somatic mosaicism}

We also analysed the effects of somatic mosaic mutations on risk of cranial meningioma formation. The rates of somatic mosaicism have been reported to be approximately $30 \%$ of de novo NF2 mutations in patients presenting with bilateral vestibular schwannomas and up to $60 \%$ in patients presenting with a de novo mutation and a unilateral vestibular schwannoma [20]. In our current cohort, $27 \%$ of patients with a new mutation were mosaic, comprising $23 \%$ of males with a new mutation and $32 \%$ of females with a new mutation.

In total, 36/64 (56\%) of individuals with mosaic NF2 had at least one cranial meningioma and the mutation position effect can still be seen in somatic mosaic individuals. Of six individuals, mosaic for a mutation in exons 14-15, only one (aged 34) had a cranial meningioma. The ages of the six individuals without meningiomas ranged from $35-63$ years.

The risk of cranial meningioma in mosaic patients was found to be greater in women $24 / 36(67 \%)$ than men 12/28 (43\%). Women with somatic mosaic disease were also at a greater risk of developing cranial meningiomas compared to women with nonmosaic NF2 ( $\mathrm{p}=0.0475)$. This effect was not seen in men, but in women the effect correlated with a significantly higher proportion of mosaic females with truncating mutations and a lower number of mutations in exons 14 and 15 than non-mosaic women. 


\section{Discussion}

Within the general population, meningiomas account for over $30 \%$ of all primary brain and central nervous system tumours (CBTRUS, 2010). NF2 disease is known to confer an increased risk of meningioma and intracranial meningiomas have been reported to occur in approximately $50 \%$ of NF2 patients. The molecular genetic factors that determine which patients will develop a meningioma are unclear.

In this study we analysed the germline mutations in a series of 411 patients with NF2, to determine whether the type and position of these mutations within the NF2 gene influence the likelihood of developing cranial meningiomas. As expected, we found that patients with a truncating mutation were more likely to have a cranial meningioma than those with a non-truncating mutation.

In addition to the effect of mutation type, we have demonstrated a clear positional effect of $N F 2$ gene mutations on the risk of developing a cranial meningioma in NF2 disease, with mutations towards the 5' end of the gene being associated with a higher prevalence of cranial meningioma. The highest risk regions for each domain occur at the junctions between domains. We did find that NF2 patients with a constitutional mutation in exon 14 or 15 may develop a cranial meningioma, although the tumours occur much less frequently in these patients and develop at a later age $(\mathrm{p}<0.001)$. A similar positional effect on disease severity in NF2 has previously been described for splice site mutations [13,14]. Although no formal statistical analysis was carried out, interestingly, no meningioma was found in any of the 13 exon 14/15 mutation-bearing individuals [14].

The positional effect was seen across all mutation types, with truncating mutations in exons 1-13 conferring a higher risk than those in exons 14 and 15 . If all truncating mutations resulted in complete loss of Merlin protein as predicted, we would 
expect to see no positional effect for this type of mutation. Therefore, our findings provide evidence that at least some nonsense or frameshift mutations must generate mutant proteins, rather than abolishing the protein product through nonsense mediated decay.

In sporadically occurring meningiomas, women are approximately three times as likely to develop a meningioma as men (CBTRUS, 2010). A female preponderance has also been reported previously within NF2 patients [21].

In contrast, several reports have shown that males are more likely to develop a meningioma within the first two decades of life [22]. Meningiomas are much less common in childhood than in adults and around $40 \%$ of childhood meningiomas occur within the context of NF2.

In our current cohort of $411 \mathrm{NF} 2$ patients, we found no evidence for an overall increased risk of cranial meningioma in females. Overall, there was no difference in risk of cranial meningioma between males and females, although our data support the finding that males are more likely than females to develop cranial meningiomas before 20 years of age. It is possible that a female preponderance after 20 years of age is masked by the increased risk to males from the predominant tumour causing diagnosis of NF2. Diagnosis with a symptomatic vestibular schwannoma in many NF2 patients gives rise to the simultaneous identification of often asymptomatic meningioma disease.

We did find that women were more likely to develop more than one cranial meningioma than men. In addition, there was an overall increased risk to women with somatic mosaic disease of developing a cranial meningioma than women with nonmosaic NF2.

In conclusion, mutations in exons 14 and 15 confer a reduced risk of cranial meningioma than mutations in exons 1-13. There is a similar risk of cranial meningioma 
for males and females with NF2 over their lifetime; however men under 20 years of age have a higher incidence of cranial meningioma. This information is of value when counselling patients about their risk of cranial meningioma. 


\section{Acknowledgments}

We would like to acknowledge John Dawson for his help with statistical analysis. The department of Genetic Medicine is supported by the NIHR Manchester Biomedical Research Centre. We would also like to thank all the patients who provided samples for the study.

\section{Competing interests}

The authors have no competing interests to declare.

\section{Licence Statement}

"The Corresponding Author has the right to grant on behalf of all authors and does grant on behalf of all authors, an exclusive licence (or non exclusive for government employees) on a worldwide basis to the BMJ Publishing Group Ltd to permit this article (if accepted) to be published in Journal of Medical Genetics and any other BMJPGL products and sublicences such use and exploit all subsidiary rights, as set out in our licence (http://group.bmj.com/products/journals/instructions-for-authors/licenceforms)." 


\section{References}

1 Evans DG, Huson SM, Donnai D, Neary W, Blair V, Newton V, Harris R. A clinical study of type 2 neurofibromatosis. $Q J$ Med 1992;84(304):603-18.

2 Evans DG, Huson SM, Donnai D, Neary W, Blair V, Teare D, Newton V, Strachan T, Ramsden R, Harris R. A genetic study of type 2 neurofibromatosis in the United Kingdom. I. Prevalence, mutation rate, fitness, and confirmation of maternal transmission effect on severity. J Med Genet 1992;29(12):841-6.

3 Mautner VF, Lindenau M, Baser ME, Hazim W, Tatagiba M, Haase W, Samii M, Wais R, Pulst SM. The neuroimaging and clinical spectrum of neurofibromatosis 2. Neurosurgery 1996;38(5):880-5; discussion 5-6.

4 Goutagny S, Kalamarides M. Meningiomas and neurofibromatosis. $J$ Neurooncol 2010;99(3):341-7.

5 Ahronowitz I, Xin W, Kiely R, Sims K, MacCollin M, Nunes FP. Mutational spectrum of the NF2 gene: a meta-analysis of 12 years of research and diagnostic laboratory findings. Hum Mutat 2007;28(1):1-12.

6 Baser ME. The distribution of constitutional and somatic mutations in the neurofibromatosis 2 gene. Hum Mutat 2006;27(4):297-306.

7 Ruttledge MH, Andermann AA, Phelan CM, Claudio JO, Han FY, Chretien N, Rangaratnam S, MacCollin M, Short P, Parry D, Michels V, Riccardi VM, Weksberg R, Kitamura K, Bradburn JM, Hall BD, Propping P, Rouleau GA. Type of mutation in the neurofibromatosis type 2 gene (NF2) frequently determines severity of disease. Am J Hum Genet 1996;59(2):331-42.

8 Evans DG, Trueman L, Wallace A, Collins S, Strachan T.

Genotype/phenotype correlations in type 2 neurofibromatosis (NF2): evidence for more severe disease associated with truncating mutations. J Med Genet 1998;35(6):450-5.

9 Parry DM, MacCollin MM, Kaiser-Kupfer MI, Pulaski K, Nicholson HS, Bolesta M, Eldridge R, Gusella JF. Germ-line mutations in the neurofibromatosis 2 gene: correlations with disease severity and retinal abnormalities. Am J Hum Genet 1996;59(3):529-39.

10 Kluwe L, Mautner VF. A missense mutation in the NF2 gene results in moderate and mild clinical phenotypes of neurofibromatosis type 2. Hum Genet 1996;97(2):224-7.

11 Baser ME, Kuramoto L, Joe H, Friedman JM, Wallace AJ Gillespie JE, Ramsden RT, Evans DG. Genotype-phenotype correlations for nervous system tumors in neurofibromatosis 2: a population-based study. Am J Hum Genet 2004;75(2):231-9.

12 Selvanathan SK, Shenton A, Ferner R, Wallace AJ, Huson SM, Ramsden RT, Evans DG. Further genotype-phenotype correlations in neurofibromatosis 2. Clin Genet 2010;77(2):163-70.

13 Baser ME, Kuramoto L, Woods R, Joe H, Friedman JM, Wallace AJ, Ramsden RT, Olschwang S, Bijlsma E, Kalamarides M, Papi L, Kato R, Carroll J, Lazaro C, Joncourt F, Parry DM, Rouleau GA, Evans DG. The location of constitutional neurofibromatosis 2 (NF2) splice site mutations is associated with the severity of NF2. J Med Genet 2005;42(7):540-6.

14 Kluwe L, MacCollin M, Tatagiba M, Thomas S, Hazim W, Haase W, Mautner VF. Phenotypic variability associated with 14 splice-site mutations in the NF2 gene. Am J Med Genet 1998;77(3):228-33.

$15 \mathrm{Xu} \mathrm{HM}$, Gutmann DH. Merlin differentially associates with the microtubule 
and actin cytoskeleton. J Neurosci Res 1998;51(3):403-15.

16 Turunen O, Sainio M, Jaaskelainen J, Carpen O, Vaheri A. Structure-function relationships in the ezrin family and the effect of tumor-associated point mutations in neurofibromatosis 2 protein. Biochim Biophys Acta 1998;1387(12):1-16.

17 Kang BS, Cooper DR, Devedjiev Y, Derewenda U, Derewenda ZS. The structure of the FERM domain of merlin, the neurofibromatosis type 2 gene product. Acta Crystallogr D Biol Crystallogr 2002;58(Pt 3):381-91.

18 Moyhuddin A, Baser ME, Watson C, Purcell S, Ramsden RT, Heiberg A, Wallace AJ, Evans DG. Somatic mosaicism in neurofibromatosis 2: prevalence and risk of disease transmission to offspring. J Med Genet 2003;40(6):459-63.

19 Wallace AJ, Watson CJ, Oward E, Evans DG, Elles RG. Mutation scanning of the NF2 gene: an improved service based on meta-PCR/sequencing, dosage analysis, and loss of heterozygosity analysis. Genet Test 2004;8(4):368-80.

20 Evans DG, Ramsden RT, Shenton A, Gokhale C, Bowers NL, Huson SM, Pichert G, Wallace A. Mosaicism in neurofibromatosis type 2: an update of risk based on uni/bilaterality of vestibular schwannoma at presentation and sensitive mutation analysis including multiple ligation-dependent probe amplification. J Med Genet 2007;44(7):424-8.

21 Evans DG, Blair V, Strachan T, Lye RH, Ramsden RT. Variation of expression of the gene for type 2 neurofibromatosis: absence of a gender effect on vestibular schwannomas, but confirmation of a preponderance of meningiomas in females. J Laryngol Otol 1995;109(9):830-5.

22 Rushing EJ, Olsen C, Mena H, Rueda ME, Lee YS, Keating RF, Packer RJ, Santi M. Central nervous system meningiomas in the first two decades of life: a clinicopathological analysis of 87 patients. J Neurosurg 2005;103(6

Suppl):489-95. 


\section{Figure legends}

Figure 1. The position of mutations in the NF2 gene affects the likelihood of developing a meningioma. The Kaplan-meier plot (a) shows the risk of meningioma within each functional domain. Gene regions are divided into exons 1-3, exons 4-6, exons 7-9, exons 10-13 and exons 14-15 or exons 1-6, exons 7-13 and exons 14-15. The bar graph (b) shows the overall risk of meningioma for mutations in individual exons. 5' regions confer a higher risk than 3' regions and exons encoding the junctions between functional domains confer a higher relative risk than the rest of the domain.

Figure 2. Truncating mutations (nonsense and frameshift) alone also show a positional effect on meningioma risk. The Kaplan-Meier plot (a) shows that exons 14 and 15 confer a lower relative risk of meningioma than exons 1-13 and (b) the bar graph shows a similar risk pattern for truncating mutations as for all mutation types combined.

Figure 3. There is no overall difference in the likelihood of developing a meningioma between males and females (a) However, males are at a higher risk of meningioma below the age of 20 years (b). 
Table 1. Effect of mutation type and position on risk of meningioma

\begin{tabular}{llllll}
\hline $\begin{array}{l}\text { Exon } \\
\text { group }\end{array}$ & $\begin{array}{l}\text { Proportion with } \\
\text { meningioma }\end{array}$ & Missense & $\begin{array}{l}\text { Nonsense or } \\
\text { frame shift }\end{array}$ & Splice site & $\begin{array}{l}\text { In frame deletion } \\
\text { or large deletion }\end{array}$ \\
\hline $\begin{array}{l}\text { Number of patients with } \\
\text { meningioma/ total NF2 } \\
\text { patients with mutation in } \\
\text { this exon group }\end{array}$ & $\begin{array}{l}\text { Number of patients with } \\
\text { meningioma/ total NF2 } \\
\text { patients with missense } \\
\text { mutation }\end{array}$ & $\begin{array}{l}\text { Number of patients with } \\
\text { meningioma/ total NF2 } \\
\text { patients with nonsense } \\
\text { or frameshift mutation }\end{array}$ & $\begin{array}{l}\text { Number of patients with } \\
\text { meningiomal total NF2 } \\
\text { patients with splice site } \\
\text { mutation }\end{array}$ & $\begin{array}{l}\text { Number of patients with } \\
\text { meningioma/ total NF2 } \\
\text { patients with in frame } \\
\text { del or large deletion } \\
\text { mutation }\end{array}$ \\
\hline $\mathbf{1 - 3}$ & $69 / 114(61 \%)$ & $2 / 9(22 \%)$ & $54 / 76(71 \%)$ & $8 / 22(36 \%)$ & $5 / 7(71 \%)$ \\
\hline $\mathbf{4 - 6}$ & $53 / 91(58 \%)$ & $3 / 4(75 \%)$ & $29 / 48(60 \%)$ & $19 / 36(53 \%)$ & $2 / 3(67 \%)$ \\
$\mathbf{7 - 9}$ & $26 / 67(39 \%)$ & $0 / 5(0 \%)$ & $16 / 30(53 \%)$ & $8 / 29(28 \%)$ & $2 / 3(67 \%)$ \\
$\mathbf{1 0 - 1 3}$ & $38 / 84(45 \%)$ & $1 / 3(33 \%)$ & $30 / 56(54 \%)$ & $6 / 20(30 \%)$ & $1 / 5(20 \%)$ \\
$\mathbf{1 4 - 1 5}$ & $13 / 55(24 \%)$ & $2 / 10(20 \%)$ & $7 / 25(28 \%)$ & $4 / 20(20 \%)$ & 0 \\
\hline Total & $199 / 411(48 \%)$ & $8 / 31(26 \%)$ & $136 / 235(58 \%)$ & $45 / 127(35 \%)$ & $10 / 18(56 \%)$ \\
\hline
\end{tabular}


$1 a$

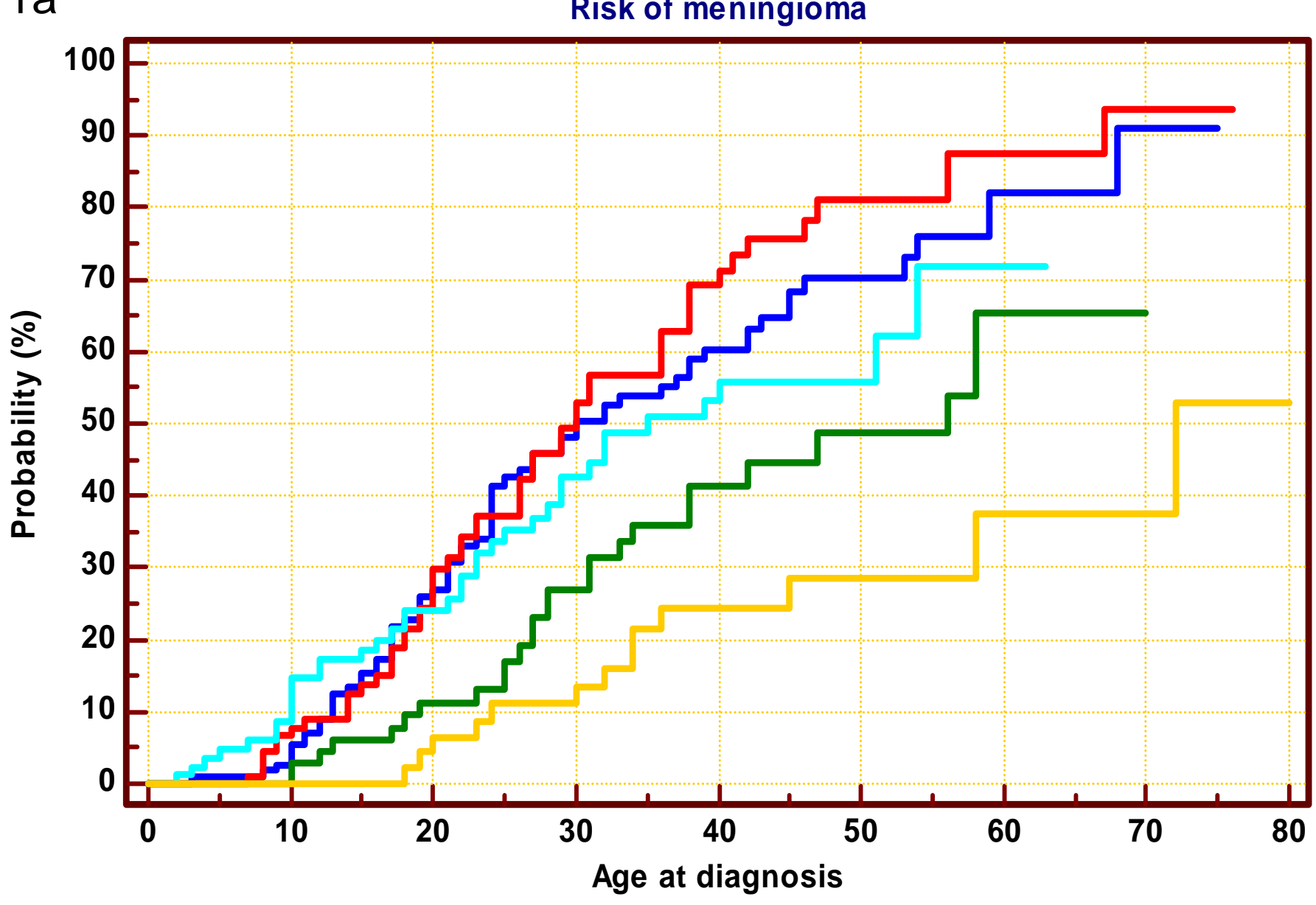

Mutation_position

- 1 . exons $1-3$

2. exons 4-6

3. exons $7-9$

4. exons $10-13$

5. exons $14-15$ 


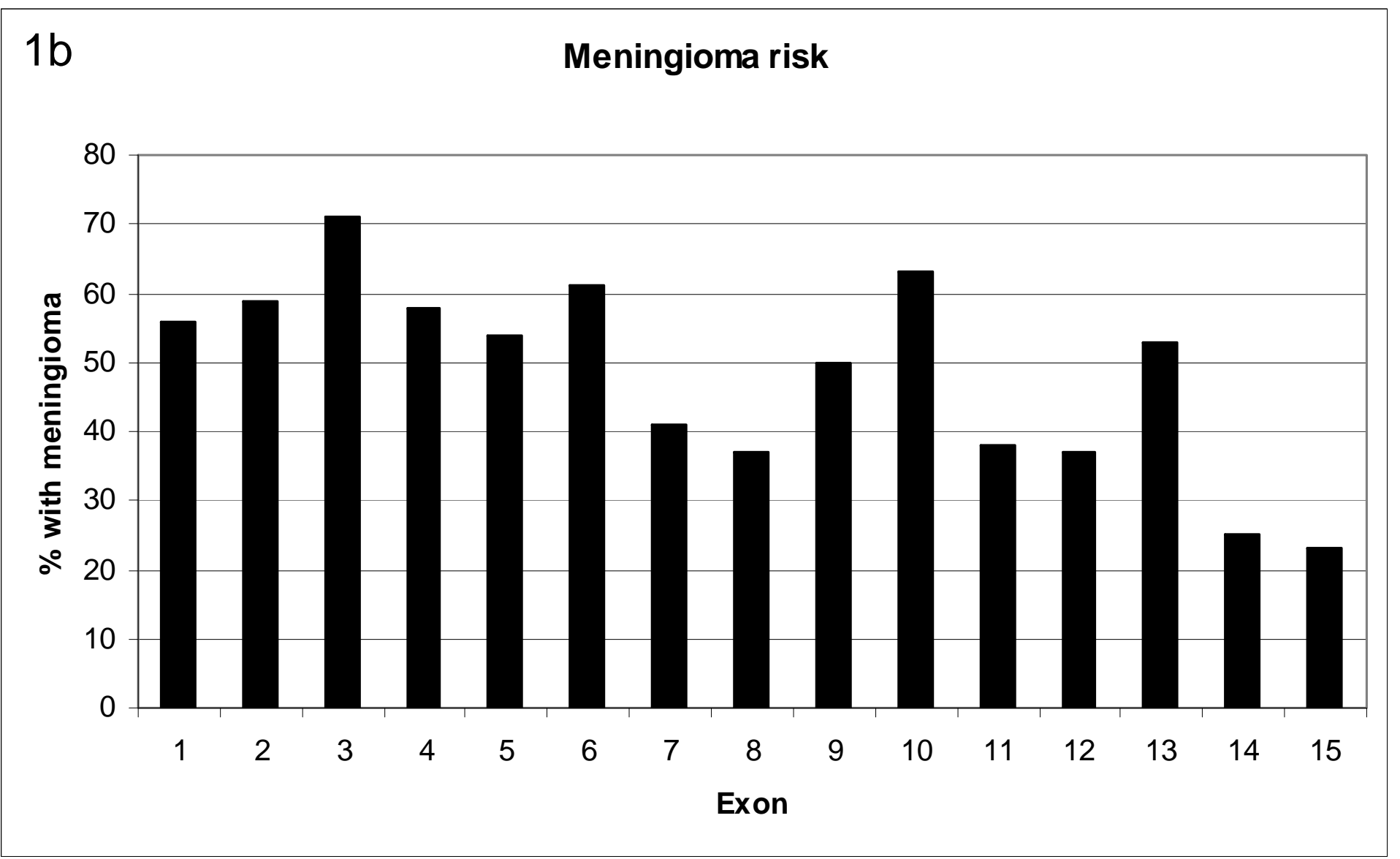




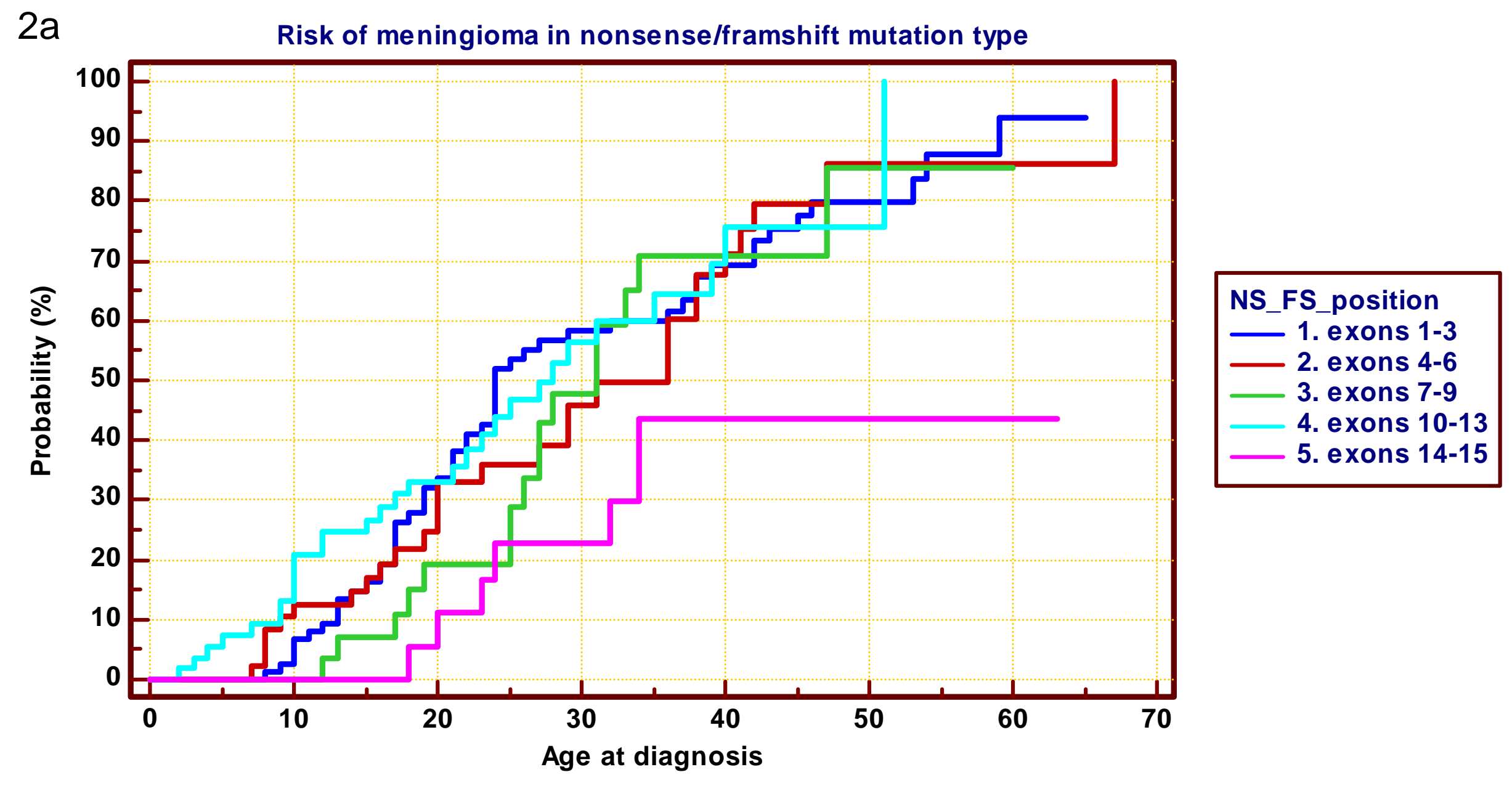




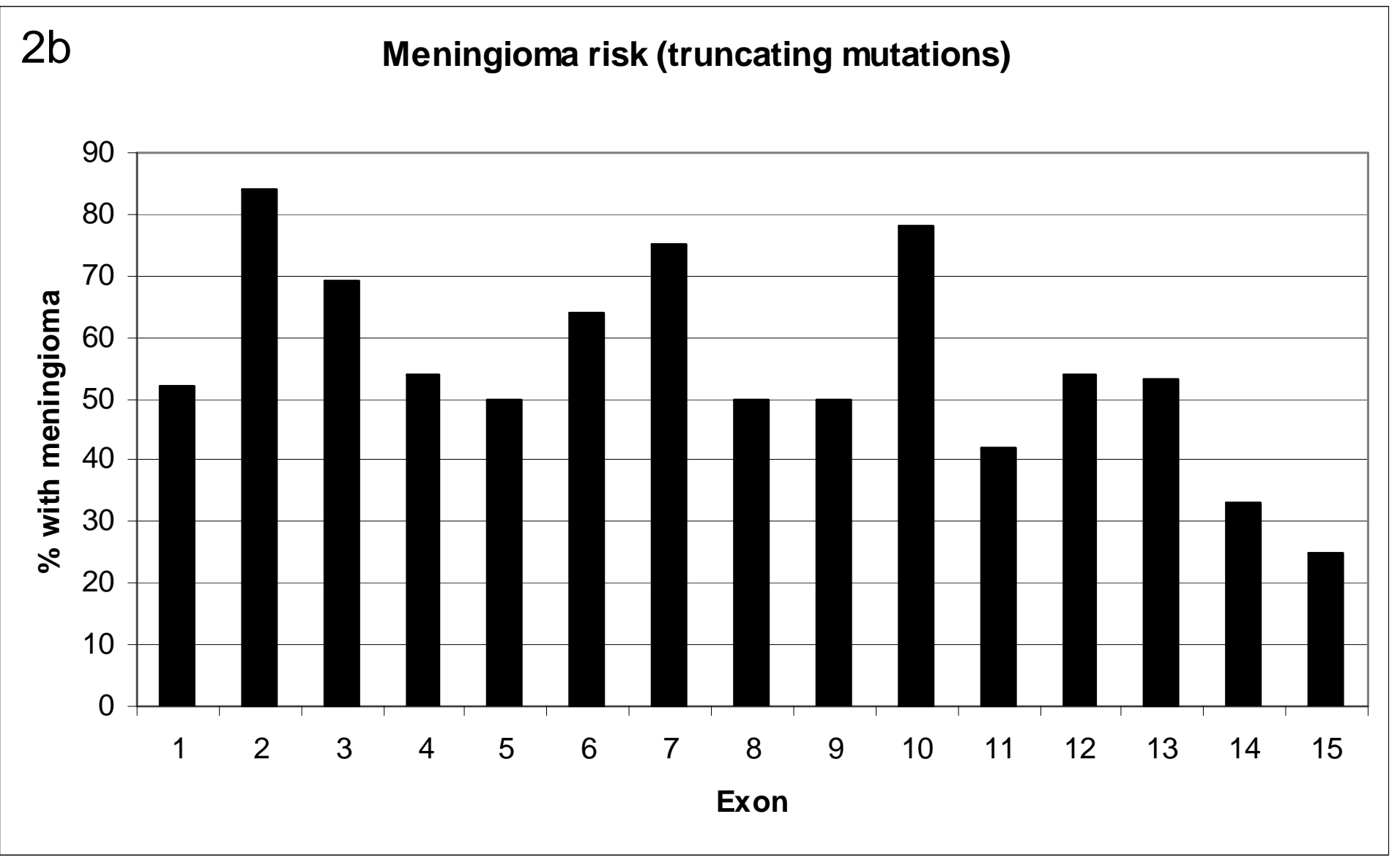




$$
3 a
$$

Risk of meningioma

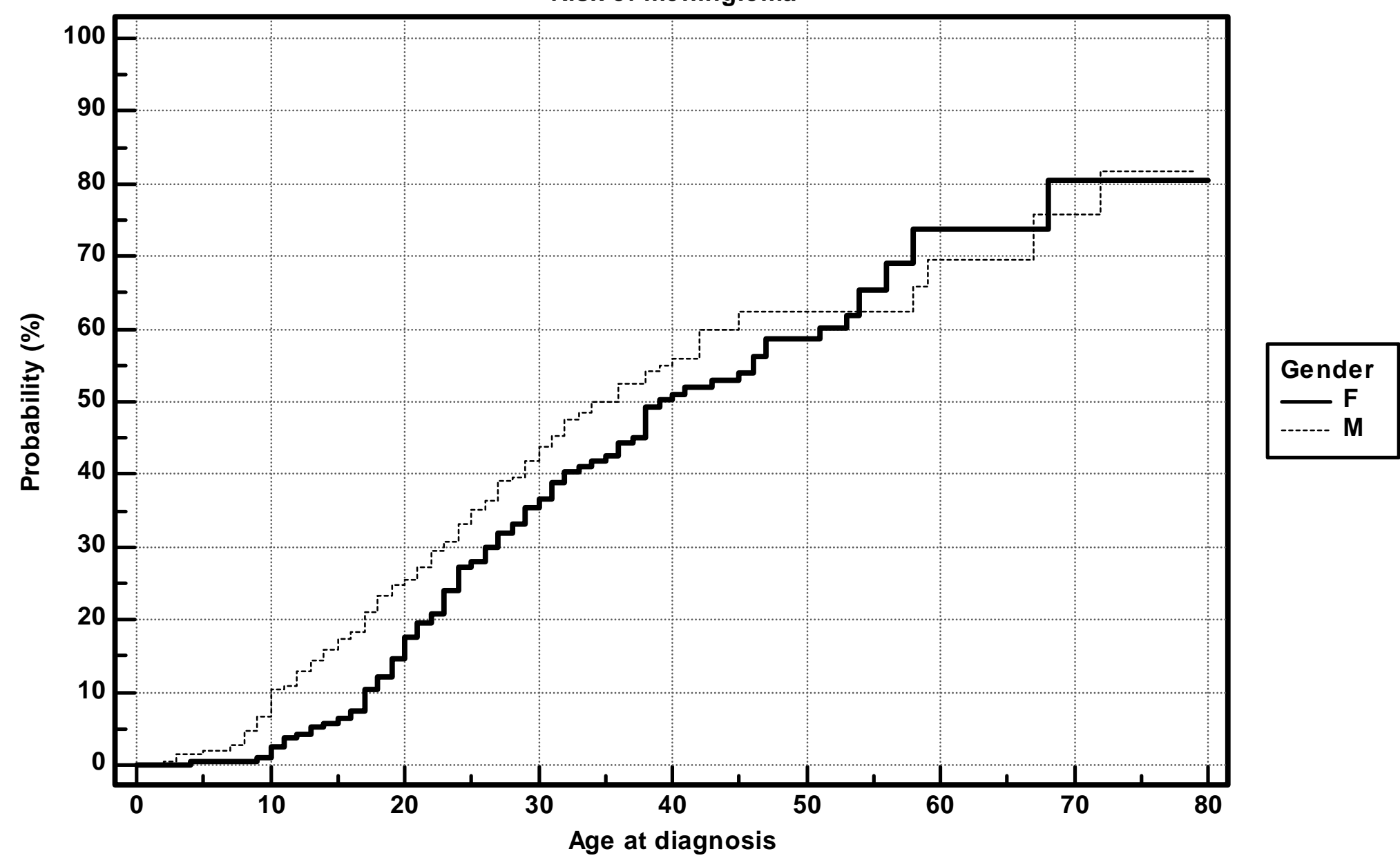




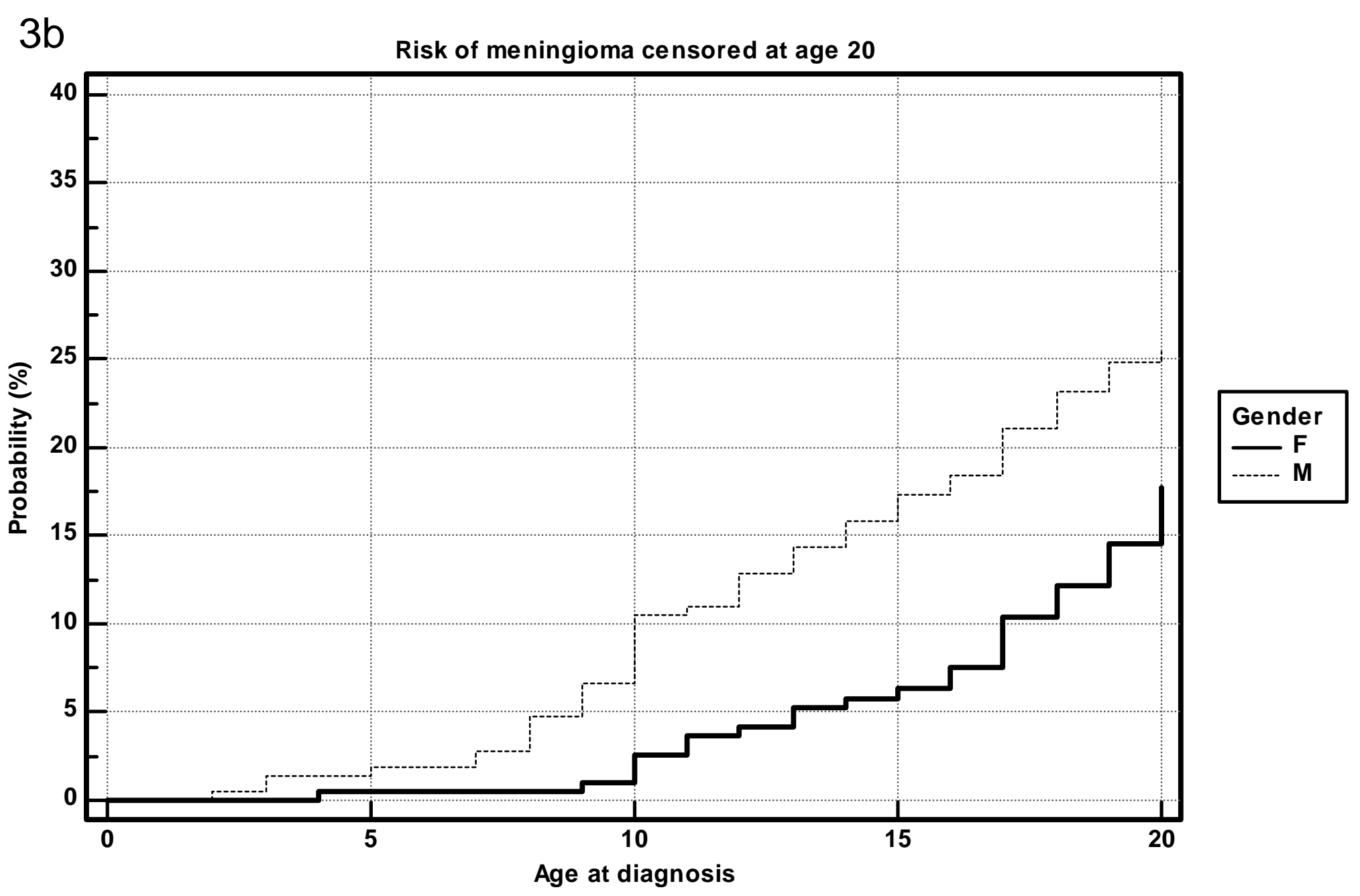

